\title{
DOCTRINA
}

\section{Normas y políticas públicas destinadas al crecimiento de las energías renovables en Chile}

\author{
Legal rules and public policies aimed to promote renewable energy in Chile
}

\section{Clemente Pérez Errázuriz \\ Guerrero Olivos Abogados, Chile}

\begin{abstract}
RESUMEN El presente artículo describe las diversas políticas públicas implementadas que han fomentado la incorporación de energías renovables en Chile, analizando la efectividad de estas políticas y concluyendo que las más visibles y onerosas no han sido, necesariamente, las más importantes para explicar el éxito en la implementación de estas energías en Chile. De tal manera, el trabajo apunta a la importancia de los nudges o impulsos en el fomento de estas energías, como mecanismos que podrían ser la clave para asegurar la efectividad en el desarrollo de las energías renovables. Lo anterior resulta relevante para la implementación de nuevas políticas públicas relativas a energías renovables, tal como sería el diseño del Plan Sectorial de Mitigación de la industria energética chilena, según lo desarrollado en el marco institucional del Proyecto de Ley de Cambio Climático, así como lección de buenas prácticas para las demás industrias responsables de la emisión de gases de efecto invernadero.
\end{abstract}

PALABRAS CLAVE Energías renovables, impuesto verde, licitaciones de suministro eléctrico, nudge, cambio climático, descarbonización.

ABSTRACT This paper describes the diverse public policies implemented to promote renewable energies in Chile, analyses their effectiveness and concluding that the most visible and onerous have not necessarily been the most important to explain the success in the implementation of these energies in Chile. The work highlights the importance of «nudges» in the promotion of these energies, as mechanisms that could be the key to ensure effectiveness in the development of renewable energies. These ideas are relevant for implementation of new public policies on renewable energy, as the design of the Sector Mitigation Policy of electric industry, in the context of the institutional framework of the draft Law on Climate Change, as a lesson in good practices for the other industries responsible for the emission of greenhouse gases. 
KEYWORD Renewable energy, green taxes, electric supply tenders, nudge, climate change, decarbonization.

\section{Introducción}

Hace algunos meses, el prestigioso diario The Washington Post señalaba, a portada completa, "Chile, la Arabia Saudita solar», para luego agregar en la bajada de la nota que: «mientras Trump propone el uso de carbón, Chile y otros países están emigrando hacia la barata energía solar». ${ }^{1}$ El propio exvicepresidente de Estados Unidos, $\mathrm{Al}$ Gore, destacó el rol que ha jugado Chile en la incorporación de las energías renovables, durante la presentación de su segundo documental sobre cambio climático, llamado La secuela inconveniente: la verdad al poder, donde afirma: "Chile está inspirando al mundo con una expansión significativa de la energía solar, más rápido que cualquier otro país en el planeta». ${ }^{2}$

Ocurre que, en el mundo entero, uno de los principales responsables de la emisión de gases de efecto invernadero es la generación eléctrica en base a combustibles fósiles. En Chile esto podría ser diferente, ${ }^{3}$ ya que durante la última década ha pasado a ser un país referente en materia de energías renovables. En solo diez años pasó de tener una industria energética altamente contaminante y emisora de gases de efecto invernadero, y ciertamente concentrada, donde solo cuatro empresas representaban cerca del 90\% de la generación, a ser una de las industrias de generación líderes en el mundo, por su alta penetración de energías renovables, de la mano de decenas de empresas de generación especializadas en este tipo de energía. Hoy en día, un 18\% de la capacidad instalada total, que asciende a $24,8 \mathrm{GW}$ es solar y eólica, lo que seguirá en aumento de forma rápida de la mano de la descarbonización.

Se han analizado poco las causas que explican este liderazgo y cambio oportuno. Acerca de este boom, se ha dicho que Chile cuenta con excelentes recursos solares, eólicos, biomasa y geotérmicos, que han gestado avances tecnológicos consistentes fundamentalmente en la reducción de precios de paneles solares y turbinas eólicas. Pero, para nada Chile es un oasis en el mundo en estos recursos y los avances tecnológicos - paneles y turbinas más baratas- son bienes transables que se encuentran a disposición de todos. Por tanto, debe haber otras causas que explican la exitosa irrupción de las energías renovables, pero poco se ha escrito sobre ellas.

1. The Washington Post, «A solar Saudi Arabia», 31 de marzo de 2017, disponible en wapo.st/3mo69nQ.

2. Catalina Ruiz Prada, ««No es suficiente cambiar los bombillos»: Al Gore regresa a Miami para advertir sobre el cambio climático», El Nuevo Herald, 6 de agosto de 2017, disponible en hrld.us/34bcuwC.

3. La generación eléctrica representa un 31\% del total de gases de efecto invernadero, mientras que el transporte un $24 \%$, y el sector industrial un $14 \%$, según el Tercer informe bienal de actualización de Chile sobre el cambio climático. Disponible en bit.ly/386NmIr. 
Tal vez se ha escrito poco, precisamente, porque cuesta identificar las medidas principales que explican este surgimiento. Por esta razón, este trabajo analiza cada una de ellas y concluye que son variados los instrumentos legales implicados, entre los que se encuentran instrumentos de protección ambiental contenidos en la Ley 19.300 sobre Bases Generales del Medio Ambiente, como también tratados internacionales, normas del mercado eléctrico, instrumentos económicos e, incluso, acuerdos voluntarios, elementos que forman un conjunto de medidas que han logrado que Chile haya sobrepasado las metas que sus propios legisladores se han impuesto.

Más destacable aún es que este crecimiento de las energías renovables se logra sin subsidios públicos de ningún tipo y con pleno cumplimiento de los principios de operación al mínimo costo y de neutralidad tecnológica que orientan la institucionalidad eléctrica.

Entonces ,las preguntas de fondo, y que este artículo intentará responder, son ¿cuál o cuáles son los factores más relevantes que han permitido el crecimiento exitoso de las energías renovables en Chile? Y ¿Cuáles son los cambios normativos que han permitido este auge? Para tal efecto, se hará un análisis cualitativo y cuantitativo, en los casos en que sea posible, de los instrumentos y normas que han resultado más determinantes en el desarrollo exitoso de las energías renovables en Chile, como también de aquellos que han sido insuficientes o inútiles.

\section{Planes sectoriales de mitigación en el Proyecto de Ley Marco de Cambio Climático}

El análisis planteado sobre qué políticas públicas o instrumentos de gestión ambiental han sido exitosos y cuáles no, es relevante por varias razones: primero, para proponer sobre la base de la experiencia, nuevas medidas o perfeccionamiento de ellas que permitan seguir avanzando en el desarrollo de estas energías en la industria de generación eléctrica chilena. Segundo, para sacar conclusiones que ayuden a avanzar en la reducción de gases de efecto invernadero a otras industrias que han sido menos exitosas en este esfuerzo, como es el caso del transporte. Por último, también puede servir para otros países que quieran observar la experiencia chilena en materia de cambio climático.

Además, es relevante hacer este análisis para que se tenga presente durante el diseño del Plan Sectorial de Mitigación de la industria energética, el más importante de todos los planes sectoriales si se considera su participación en el Inventario de gases de efecto invernadero del Ministerio del Medio Ambiente, ${ }^{4}$ de acuerdo con el marco institucional diseñado por el Proyecto de Ley de Cambio Climático que actualmente se encuentra en tramitación legislativa.

4. Disponible en bit.ly/3mhLDoL. 
Este borrador de proyecto de ley contempla, como estrategia para que Chile pueda cumplir con sus objetivos climáticos y con los compromisos adquiridos con la comunidad internacional (la contribución nacional determinada en el contexto del Acuerdo de París de 2015), la definición de:

- una meta, que podrá ser incrementada;

- una institucionalidad para alcanzar esta meta, en particular un Consejo de Ministros para la Sustentabilidad y el Cambio Climático, un Consejo Nacional y un Comité Científico Asesor;

- la elaboración de una estrategia climática de largo plazo; y

- el mandato de diseñar e implementar Planes Sectoriales de Mitigación y de Adaptación.

Sin embargo, el Proyecto de Ley de Cambio Climático no cuenta con medidas para alcanzar las metas propuestas. Todo dependerá de los Planes Sectoriales de Mitigación y Adaptación, que son de carácter administrativos, vale decir, de una naturaleza jurídica de menor jerarquía que la ley.

Nuestra impresión es que el debate público durante la discusión de este proyecto de ley, la discusión política y, para qué decir, las redes sociales, se van a concentrar en la meta y sus posibles incrementos, es decir, sólo el primero de todos los puntos contenidos en dicho proyecto de ley, mientras que los demás: institucionalidad, instrumentos, las políticas públicas, los «dientes» con que el Estado deberá lograr estas metas, podrían pasar, desgraciadamente, a un segundo plano.

En una economía como la chilena, donde la mayor parte de las decisiones de inversión las toma el sector privado, tanto o más importante que la meta que se defina legalmente, son los instrumentos que se utilizarán para alcanzarla. Esta discusión de metas versus instrumentos no es nueva en derecho ambiental chileno. Muchas veces se ha discutido si se debe privilegiar el establecimiento de normas de calidad ambiental (equivalentes a la definición de metas), versus normas de emisión y otros instrumentos necesarios para lograr la calidad ambiental deseada.

Obviamente ambas son necesarias, buenas metas e instrumentos. No basta con definir metas ambiciosas, si no se tienen las herramientas correspondientes. Este sería el caso del hermano del medio en la fábula de tres hermanos que canta Silvio Rodríguez:

De tres hermanos el de en medio se fue/ Por la vereda a descubrir y a fundar / Y para nunca equivocarse o errar / Iba despierto y bien atento al horizonte igual / Pero este chico listo no podía ver / La piedra, el hoyo que vencía a su pie / Y revolcado siempre se la pasó / Y se hizo viejo, queriendo ir lejos, a donde no llegó.

Por ejemplo, la norma de calidad en ozono es muy ambiciosa, y simplemente no se cumple en muchas ciudades del país durante gran parte del año. Por eso, no basta 
una meta ambiciosa, sino que lo que importa, a la larga, es lo que se logre, sobre todo en un esquema de plazos largos y gobiernos cortos, sin reelección.

Un esquema burocrático en el que simplemente unos establecen metas a otros, no garantiza mayores avances. ¿De qué sirve, por ejemplo, que el Consejo de Ministros le pida al Ministerio de Minería que defina un porcentaje de reducción de gases de efecto invernadero para las grandes actividades extractivas? ¿O que el de Vivienda y Urbanismo diga que buscará reducir las emisiones de los proyectos inmobiliarios, pero no señale cómo? ¿Qué van a hacer si no tienen un arsenal adecuado? El riesgo es que se sumen documentos burocráticos sin medidas reales y efectivas de reducción de emisiones contaminantes. Por ello, la experiencia de la industria energética, tal vez la más relevante en este ámbito, debe ser analizada de cerca.

\section{Diagnóstico de la matriz energética previa incorporación de las energías renovables no convencionales}

Hace cinco años, Chile se caracterizaba por tener una industria de generación concentrada y una matriz no renovable. El sistema eléctrico chileno funciona bajo los principios de neutralidad tecnológica y de operación a mínimo costo. Pese a ello, algunos incentivos se han ido implementando en favor de estas fuentes de generación. Pero antes de entrar a analizar dichos incentivos, cabe señalar que Chile sufrió precios altos y estrechez energética hasta hace pocos años. El origen de esta crítica situación se remonta, en primer lugar, al desabastecimiento de gas natural proveniente de Argentina, a años de sequías que afectaron la generación hidroeléctrica de importante participación en la matriz y, luego, a la dificultad de aprobación ambiental de muchos proyectos emblemáticos, tales como el proyecto hidroeléctrico HidroAysén o las centrales de Energía Austral, como la central hidroeléctrica Río Cuervo. El punto es que hace solo algunos años el Centro de Despacho Económico de Carga del Sistema Interconectado Central preveía déficit de energía para el 2013 en un escenario de hidrología seca o de problemas de suministro de diésel y recomendaba postergar el mantenimiento de diversas centrales durante los meses de invierno. O sea, hasta hace poco, el sistema eléctrico chileno se encontraba en una situación sumamente vulnerable y dependiente de factores externos como la hidrología, con riesgo de racionamiento y con una parte del sistema operando en base a diésel, combustible caro y contaminante.

Siete años antes, Chile no contaba con proyectos que permitieran enfrentar este déficit de generación de energía eléctrica. Los proyectos que vendrían a aportar capacidad instalada al país, en especial termoeléctricas y centrales de embalses, no lograban la calificación ambiental favorable y como consecuencia de lo anterior, los precios se dispararon. ¿Y las energías renovables? Esas sí contaban con autorización ambiental, pero no podían ejecutarse por dificultades de conexión al sistema interco- 
nectado (no había capacidad para evacuar la energía, produciéndose un «desacople» del sistema) y por la falta de contratos de suministro (PPA, del inglés Power Purchase Agreement) que permitieran establecer las condiciones de estabilidad económica necesarias para obtener los financiamientos para su ejecución.

La dificultad de conexión impactaba en mayor medida a las centrales de energías renovables, que por acceso al recurso habitualmente se encuentran más dispersas que las termoeléctricas. Respecto de los contratos de suministros, la intermitencia o variabilidad de las energías renovables, sumado a la falta de confianza en estas fuentes de energía, les hacía muy difícil obtenerlos. Además, había una gran concentración en la industria de generación eléctrica, tal como lo describió el mensaje del proyecto de ley destinado a mejorar las licitaciones de suministro eléctrico de empresas distribuidoras: «En el SIC, las tres empresas más grandes de generación eléctrica y sus relacionadas, poseen más de un $76 \%$ de la capacidad instalada, mientras que en el SING alcanza el $98 \% » .^{5}$

En suma, los precios de la energía eran suficientemente altos y la demanda en constante alza, por lo que no sería necesario plantearse la necesidad de subsidios, tipo feeding tariffs para la generación de energías renovables, como sí lo había hecho Europa. Persistía entonces la pregunta: ¿por qué si existe un enorme potencial para estas energías en Chile y los precios estaban comparativamente muy altos, no se habían desarrollado más?

Tal como se señaló, hace siete años atrás Chile tenía una industria de generación concentrada, una matriz de energía tradicional y los contratos de suministro que licitaban las empresas de distribución se declaraban desiertos, pese a los altos precios imperantes. ¿Cómo se logró desconcentrar esta industria, haciéndola renovable al mismo tiempo, y sin subsidios de ningún tipo? Esa es la incógnita que se intentará resolver.

\section{Políticas públicas de promoción de las energías renovables}

A continuación, se analizará un conjunto de instrumentos o medidas que se han implementado, en la mayoría de los casos, para promover las energías renovables. Algunas con mayor y otras con menor éxito. Por eso, se explicará brevemente cada una de ellas, y luego se hará un análisis de su efectividad, para sacar conclusiones y recomendaciones de política pública.

5. Cámara de Diputados, Boletín 9515-08: Proyecto de Ley que introduce modificaciones a la Ley General de Servicios Eléctricos perfeccionando el sistema de licitaciones de suministro eléctrico para clientes sometidos a regulación de precios, 19 agosto 2014, pág. 14. Disponible en bit.ly/3qVGbM3. 


\section{Incentivos directos para las energías renovables no convencionales en Chile}

Los esfuerzos para incorporar energías renovables empezaron antes del momento crítico que se ha descrito. La Ley 20.257 de $2008^{6}$ creó instrumentos para la diversificación de la matriz energética a través de fuentes de Energías Renovables No Convencionales. Respecto de la dificultad de conexión a la red, se procedió a desarrollar un fuerte plan de integración de los Sistemas Interconectados Central y del Norte Grande, además de que se aprobaron proyectos de ley tendientes a simplificar los procedimientos para la obtención de concesiones eléctricas.

Los principales beneficios disponibles para las energías renovables son los siguientes:

\section{Exención de peajes de transmisión troncal}

La llamada Ley Corta 1,7 que incorporó el artículo 71.7 de la Ley General de Servicios Eléctricos (LGSE) ya derogado, creó los primeros incentivos, introduciendo el concepto de las denominadas Energías Renovables No Convencionales, que incluye la energía geotérmica, eólica, solar, biomasa, mareomotriz, pequeñas centrales hidroeléctricas (hasta $20 \mathrm{MW}$ ), cogeneración y otras similares.

Una de las herramientas contenidas en la Ley Corta 1 para viabilizar proyectos de energías renovables no convencionales de pequeña y mediana escala fue la exención en el pago de peajes de transmisión troncal establecida en beneficio de este tipo de proyectos de hasta $20.000 \mathrm{~kW}$. Para proyectos cuyos excedentes de potencia fueran entre o y $9.000 \mathrm{~kW}$ la exención era total, mientras que para proyectos con excedentes de potencia entre 9.000 y $20.000 \mathrm{~kW}$ la exención fue parcial.

Este beneficio fue finalmente derogado el año 2016 por le Ley 20.936 o Ley de Transmisión, ${ }^{8}$ que optó por transferir la obligación de pago de peajes desde los generadores hacia los clientes finales. Se trató de un incentivo menor, cuyo principal aporte fue el ser uno de los primeros incentivos que se implementó en esta materia.

6. Ley 20.257, introduce modificaciones a la Ley General de Servicios Eléctricos respecto de la generación de energía eléctrica con fuentes de energías renovables no convencionales, del 1 de abril de 2008. Disponible en bit.ly/3afVNE7.

7. Ley 19.940, regula sistemas de transporte de energía eléctrica, establece un nuevo régimen de tarifas para sistemas eléctricos medianos e introduce las adecuaciones que indica a la ley general de servicios eléctricos, de 13 de marzo de 2004. Disponible en bit.ly/30QA3md.

8. Ley 20.936 establece un nuevo sistema de transmisión eléctrica y crea un organismo coordinador independiente del sistema eléctrico nacional, de 20 de julio 2016. Disponible en bit.ly/3nlSsar. 


\section{Precio estabilizado para Pequeños Medios de Generación $y$ de Generación Distribuida}

El otro incentivo creado por la Ley Corta 1 fue la institución de los Pequeños Medios de Generación (PMG) y de Generación Distribuida (PMGD), por la cual se permitió a los generadores de $9 \mathrm{MW}$ o menos - de fuentes renovables o no-, vender su energía y potencia a través de una opción adicional denominada precio estabilizado y gozando de autodespacho en su inyección al sistema.

El precio estabilizado corresponde al precio de nudo de corto plazo de energía, determinado semestralmente por la Comisión Nacional de Energía mediante decreto. Este es un precio teórico cuyo objetivo es acercarse a un promedio de los precios de mercado de corto y largo plazo.

Esta opción de vender a un precio estabilizado, bastante ignorado en un principio porque no representaba un claro beneficio en términos de precio, pronto empezó a cobrar popularidad porque permitió a los desarrolladores vender su energía como si tuvieran un contrato de suministro y, por ende, acceder a financiamiento bancario para sus proyectos (Mardones, 2019). Comenzó entonces una fuerte actividad de desarrollo de proyectos pequeños distribuidos a lo largo y ancho del valle central.

Actualmente, los generadores que se acogen a precio estabilizado constituyen cerca de un $2 \%$ de la capacidad instalada del sistema solamente, pero en fuerte crecimiento, fundamentalmente de la mano de proyectos fotovoltaicos de menos de 9 MW para acogerse al precio estabilizado y muy preferentemente de menos de $3 \mathrm{MW}$, para así evitar tener que ingresar al Sistema de Evaluación de Impacto Ambiental (SEIA).

La posibilidad de acceder al financiamiento bancario y la rapidez de su desarrollo, han hecho que el precio estabilizado constituya un incentivo muy valorado por la generación de energías renovables y, como se verá más adelante, se ubicará entre las medidas exitosas que explican el auge de estas energías en Chile.

\section{Atributo Energía Renovable No Convencional}

Un tercer incentivo creado para promover energías renovables está contemplado en la Ley 20.257 que reformó la Ley General de Servicios Eléctricos respecto de la generación de energía eléctrica con fuentes de energías renovables no convencionales. Esta ley, en su artículo 150 bis, dispuso que a partir del año 2010, aquellas empresas eléctricas que efectúen retiros de energía con capacidad instalada superior a $200 \mathrm{MW}$ debían acreditar que una proporción de esos retiros proviene de energía generada por medios de energías renovables no convencionales. Esta obligación sería gradual, siendo de un 5\% para los años 2010 a 2014 y anualmente aumentada en un 0,5\% a partir del año 2015, para alcanzar un 10\% el año 2024. En caso de incumplimiento, 
las generadoras debían pagar un cargo de o,4 UTM por cada MW/hora de déficit respecto de su obligación. Las generadoras pueden cumplir el porcentaje requerido ya sea a través de proyectos propios o mediante la compra de energía a proyectos de energías renovables.

Poco tiempo después, en el año 2013, se modificó el calendario señalado para mejorar el incentivo. Hubo mucho debate político sobre las nuevas metas de penetración que se proponía lograr en la matriz energética por parte de estas energías. Por un lado, se observaba un fuerte interés de los legisladores de agilizar la incorporación de las energías renovables no convencionales y, por otra, había estudios que preocupaban al sector empresarial. Estos estudios estimaban que la Ley 20.257 aumentaba el costo de suministro para los consumidores del Sistema Interconectado Central en a lo menos US $\$ 4.000$ millones en valor presente (Galetovic y Muñoz, 2008). Una modificación a esta norma en la forma señalada podría traer aparejado un aumento de precios en la energía que podría superar el 30\% algunos años, «con lo que la tarifa residencial podría subir más de $5 \%$ en forma permanente» (Jiménez, 2011).

Pese a estos estudios que resultaron ser alarmistas y equivocados, se aprobaron nuevas metas para cumplir con el incentivo, adelantando el cronograma de porcentaje de Energías Renovables No Convencionales establecido en la Ley 20.257, a fin de establecer la meta que se ha denominado 20/25: desde un $10 \%$ al 2024, se modificó al $20 \%$ al año 2025 .

Este incentivo es una especie de subsidio cruzado y se denomina "Atributo ERNC». El valor de la multa constituye el techo de lo que se puede obtener como incentivo. Los valores de mercado del atributo ERNC dependen, en definitiva, de la oferta y la demanda, ${ }^{9}$ equilibrio que depende del sistema eléctrico en que se encuentre: a mayor oferta de energías renovables, menor será el valor del atributo ERNC.

Desgraciadamente, como se verá más adelante, este incentivo que resultaba ser el más abierto y con un apoyo transversal para las energías renovables, no ha logrado ser un real impulso para estas tecnologías como se esperaba. Ya sea porque las cuotas prometidas eran muy bajas o porque la sanción por incumplimiento era pequeña, el hecho es que hubo otras medidas más valoradas e incidentes para el desarrollador de proyectos de generación. Ni siquiera después de la Ley 20.257 que incrementó las cuotas de energías renovables, se ha desarrollado un mercado poderoso de atributos ERNC, debido a que la generación renovable ha ido superando ampliamente las cuotas previstas. Se ha producido entonces, una especie de «sobreoferta» de atributos ERNC, que ha llevado los precios a valores insignificantes.

9. Valores actuales que conocemos ascienden a la mitad de la multa establecida, vale decir, unos $\$ 16$ USD MWh. 


\section{Facilidades en licitación de las empresas de distribución eléctrica}

El déficit de generación eléctrica debido a los cortes de suministro de gas desde Argentina y a la paralización de proyectos en su evaluación ambiental o por medio de su judicialización, se tradujo en una crisis de suministro para las empresas de distribución eléctrica. Por disposición legal, estas deben celebrar contratos de suministro por medio de licitaciones públicas dirigidas por el Ministerio de Energía. Sin embargo, las licitaciones de suministro realizadas durante el período crítico comentado tuvieron que ser declaradas desiertas o adjudicadas a valores extraordinariamente altos. En la licitación de diciembre de 2013, por ejemplo, los generadores fueron adjudicados a un valor promedio de US 128 por MWh, el doble de 2006.

Las energías renovables no podían desarrollar sus proyectos por falta de contratos de suministro. No se entendía qué ocurría pues se prometía energía más barata, pero no se podían desarrollar los proyectos porque no eran bancables, dado que carecían de contratos. Y la base principal de contratos, a saber, las licitaciones de suministro de las distribuidoras no recibían ofertas o se adjudicaban a valores muy altos. Algo no estaba funcionando en el prestigioso modelo institucional chileno de regulación del mercado eléctrico.

El mal resultado de los procesos de licitación de suministro para las empresas de distribución incluso motivó un estudio de la Fiscalía Nacional Económica, que propuso medidas que resultarían fundamentales en el cambio sustantivo que ha tenido la industria de generación eléctrica en los últimos años. Este estudio, si bien descarta conductas del tipo colusivas, concluye que «el comportamiento de la oferta es consistente con modelos de competencia oligopolística» (Fabra, Montero y Raguant, 2014: 65). Producto de ello, no solo se impedía a las energías renovables competir con éxito, sino que concluía que «los consumidores más pequeños enfrentan precios más altos» (Fabra, Montero y Raguant, 2014: 65), lo que precisamente el sistema de licitaciones públicas busca evitar. También detecta que las empresas de generación están cobrando una alta prima de riesgo por comprometerse a vender a un cierto precio, «cuando sus costos de oportunidad son volátiles e inciertos» (Fabra, Montero y Raguant, 2014: 66).

Entre las medidas que este estudio propone, se encuentran las siguientes:

- extender el uso de las subastas o licitaciones al mercado de los clientes libres, especialmente los de menor tamaño;

- permitir a los clientes libres acceder a participar directamente en el mercado spot;

- mejorar el diseño de las subastas, simplificándolas; y

- que las autoridades regulatorias y de competencia intervengan en el mercado 
para mejorar su funcionamiento, «sin que para ello sea necesario disponer de evidencia sobre colusión tácita o explícita».

Sobre la base de estas recomendaciones, y más aún, debido a que los altos costos de la energía ya estaban afectando a las familias y a la productividad nacional, el gobierno de Michelle Bachelet decidió implementar un conjunto de medidas que se podrían llamar «facilidades en las licitaciones de las empresas de distribución», destinadas a: «i) disminuir los precios de la energía eléctrica; ii) aumentar la competencia en el sector elétrico; iii) incorporar nuevos actores en el segmento de generación, disminuyendo las barreras de entrada; y iv) diversificar las fuentes de energía» (Rudnick y Romero, 2018).

En primer lugar, la mayor parte de estos cambios se hicieron simplemente a través de variaciones en las bases de licitación y luego se incorporaron en un conjunto de modificaciones a la Ley General de Servicios Eléctricos, realizadas a través de la Ley $20.805^{:{ }^{10}}$

- Se amplió el plazo de duración de los contratos de 15 a 20 años, facilitando el financiamiento de los proyectos que permitirán generar la energía ofertada.

- Se amplió el plazo para iniciar el suministro, a fin de dar el tiempo suficiente para que nuevos proyectos de generación pudieran ser desarrollados, financiados y construidos.

- Se establecieron bloques horarios para que energías renovables que solo generan durante parte del día (como las solares y eólicas), pudieran ofertar, sin tener que comprometerse a suministrar las 24 horas del día.

- Se flexibilizaron los contratos en favor de los desarrolladores, permitiendo, por ejemplo, posponer el inicio del período de suministro, como también se contempló el término anticipado de los contratos adjudicados por parte de generadores que respaldaron su oferta con proyectos nuevos, en caso de demoras no atribuibles a dichos generadores.

- Se amplió el rango de clientes que pueden optar a ser regulados o libres, esto es desde $500 \mathrm{~kW}$ hasta $5.000 \mathrm{~kW}$-antes el techo era de $2.000 \mathrm{~kW}$-, lo que permite aumentar la cantidad de energía a licitar y mejorar las condiciones de negociación de los clientes libres de menor tamaño.

Estos cambios en las licitaciones de suministro tuvieron efectos de inmediato y de un éxito notable. Las dos subastas realizadas el año 2015, al amparo de las nuevas disposiciones legales, lograron un enorme interés de la industria renovable, que contras-

10. Ley $\mathrm{N}^{\circ} 20.805$, perfecciona el sistema de licitaciones de suministro eléctrico para clientes sujetos a regulaciones de precios, de fecha 29 de enero de 2015. https://www.leychile.cl/Navegar?idNorma=1074277 
taba con la apatía de los procesos anteriores que, como se ha visto, fueron declarados desiertos o adjudicados a precios muy altos a energías de combustibles fósiles. Tanto así que, en el primer proceso, participaron un total de 31 empresas, mientras que en el segundo participaron 84 empresas. Esta segunda subasta:

No solo marcó un récord en cuanto a precios de la energía, donde las ofertas fluctuaron entre los US $\$ 29,1 \mathrm{MWh}$ y los US $\$ 200 \mathrm{MWh}$, con un precio promedio de adjudicación de US\$ 47,6 MWh y con un 100\% de la energía adjudicada, sino también significó un hito en términos de participación, con 84 empresas que efectuaron un total de 686 ofertas, por un total de $85.278 \mathrm{GWh} /$ años, equivalente a siete veces la energía licitada (Comisión Nacional de Energía, 2017: 8).

La competencia permitió una reducción inédita en los precios adjudicados ${ }^{11}$ y lo más sorprendente para la opinión pública fue que cerca del 50\% de la energía adjudicada recayó en energías renovables no convencionales, siendo 2/3 de ellas en centrales eólicas y solares.

\section{Normas de «comando y control» que han afectado a las empresas de generación tradicional}

El sector de energías renovables puede haberse beneficiado no solo por los incentivos directos antes descritos, sino también por las mayores exigencias impuestas a las energías tradicionales, su competencia. La demanda por energía ha venido creciendo, pero las formas de suplir esa demanda necesariamente van a cambiar si Chile repentinamente se queda sin suministro de gas - lo que ocurrió, como se sabe, a partir del año 2005- y luego los proyectos de energía tradicional que se planificaron para reemplazar estas centrales no lograron contar con la autorización ambiental o con la legitimación social necesaria para poder ejecutarse.

Por esta razón, se han considerado dos instrumentos de gestión ambiental del tipo «comando y control», vale decir, de regulación directa, que han contribuido al desarrollo de las energías renovables, por la vía de dificultar el desarrollo de las energías tradicionales.

\section{Evaluación ambiental de proyectos tradicionales de generación}

La paralización, rechazo o judicialización de los principales proyectos de energía tradicional es un hecho público, que para algunos fue una buena noticia, mientras que

\footnotetext{
11. Máximo Pacheco, ministro de Energía de la época, indicó que el precio promedio de adjudicación es de US\$ 47,6 MWh. En esta licitación se situaron un $63 \%$ por debajo de lo obtenido en la última licitación del gobierno anterior, cuando la energía fue adjudicada a US $\$ 129$ el MWh. Información disponible en bit.ly/37jOHwp.
} 
para otros fue motivo de indignación. Y los caminos que este proceso ha tomado han sido diversos: en algunos casos, ha sido un rechazo de la autoridad ambiental, en otros, de los Tribunales de Justicia o de gestiones que se han realizado por sobre la institucionalidad ambiental, como es el caso del famoso «telefonazo» de Barrancones, referido a la solicitud telefónica que hizo el presidente Sebastián Piñera en su primer mandato al titular de un proyecto termoeléctrico, para que no perseverara en él.

Las causas de la paralización de proyectos de energía tradicional son diversas. Tienen que ver con una mayor exigencia ambiental, tanto por la autoridad como por parte de las comunidades, a los proyectos que generan externalidades negativas. Se observan comunidades más empoderadas, normas ambientales más exigentes, una opinión pública más activa en redes sociales y manifestaciones públicas, como también la intervención de otros poderes del Estado, en particular del Poder Judicial, más deliberante y menos observante de las decisiones de los servicios públicos competentes.

Según algunos autores, las principales causas de la creciente oposición que enfrentan los proyectos son (Bernstein, Bitrán, Jadresic y Tokman, 2013):

- una ciudadanía más empoderada, participativa y preocupada del cuidado del medio ambiente, que se organiza y moviliza para oponerse a los proyectos que ella considera que tienen impactos ambientales negativos;

- una comunidad local menos dispuesta a aceptar inversiones que tienen una distribución geográfica inequitativa de los costos y los beneficios; y

- una creciente competencia por el uso del territorio entre distintos fines productivos y de preservación.

Con todo, si se trata de emisiones de gases de efecto invernadero al menos, cabe notar que no solo se han rechazado u obstaculizado centrales termoeléctricas, sino también proyectos de energías renovables, desde proyectos hidroeléctricos de gran escala, como es el caso de los proyectos HidroAysén o las centrales de Energía Austral, ambos en la región de Aysén, a proyectos eólicos y solares.

Cualquiera sea el caso, el hecho es que los proyectos complejos de energías tradicionales han visto numerosos obstáculos para obtener la autorización ambiental, a diferencia de los proyectos de menor escala, especialmente solares y eólicos. La respuesta no se hizo esperar. Las grandes generadoras revisaron sus carteras de proyectos y optaron por energías renovables de escalas más pequeñas y con menor oposición comunitaria. ${ }^{12}$

12. Luca D’Agnese, gerente general de Enersis de la época, afirmaba: «Estoy $100 \%$ seguro de que nunca vamos a hacer 3.00o MW en Chile en los próximos años». Nueva Minería y Energía, 31 de agosto de 2015, disponible en bit.ly/34dgdgm. 


\section{Norma de emisión para centrales termoeléctricas}

El año 2011 se dicta, luego de un serio proceso de priorización y realización de estudios, el Decreto Supremo 13 de 2011, que establece la norma de emisión para centrales de generación termoeléctrica de capacidad superior a los 50 MW. Las normas regulan las emisiones al aire de material particulado (MP), óxidos de nitrógeno (NOx), dióxido de azufre $\left(\mathrm{SO}_{2}\right)$ y mercurio $(\mathrm{Hg})$, de cumplimiento obligatorio en todo el territorio nacional, y con monitoreo continuo en el efluente de la fuente emisora, lo que además implica una exigencia de inversión adicional.

La entrada en vigencia de esta norma fue escalonada, con un plazo mayor para centrales existentes. Hoy en día la Superintendencia de Medio Ambiente cuenta con un software que se conecta directamente con los datos que disponen las empresas en sus unidades de generación, lo que le permite recibir en línea la información de los principales componentes que se emiten a la atmósfera. ${ }^{13}$

El objetivo de estas normas no es el de reducir las emisiones de gases de efecto invernadero, sino de disminuir los efectos adversos sobre la salud de las personas y los ecosistemas a través de una reducción de las emisiones de tres de los principales contaminantes atmosféricos. Se planteó como una norma necesaria, por cuanto, se afirmaba:

El mercado chileno no incorpora mecanismos para maximizar la eficiencia de las centrales generadoras. En efecto, la ausencia de exigencias para mejorar la eficiencia o para repotenciar las termoeléctricas permite la existencia de centrales de bajo rendimiento, lo cual aumenta las emisiones de contaminantes. Es así como el sector termoeléctrico presenta una participación importante en las emisiones de PM (38\%), $\mathrm{SO}_{2}(27 \%)$ y $\mathrm{NOx}(34 \%)$ y mercurio $(\mathrm{Hg}, 59 \%)$ a nivel país (Libertad y Desarrollo, 2011: 8).

Las inversiones que esta nueva norma provocó se estimaron en un monto aproximado de USD 1.000 millones, ${ }^{14}$ cifra relevante para una norma ambiental, más aún si se considera que el grupo de empresas obligadas - fruto de la propia concentración de la industria-, era bastante pequeño.

En suma, por las dificultades de aprobación ambiental y por el monto requerido para implementar compensaciones sociales y sistemas de abatimiento y monitoreo que cumplan con las nuevas normas de emisión, es evidente que todo esto ha afectado decisivamente - aunque imposible definir un valor exacto- el desarrollo de la energía termoeléctrica y promovido, en reemplazo, el de las energías renovables.

13. Superintendencia del Medio Ambiente, «SMA lanza Sistema de Monitoreo Online para Centrales Termoeléctricas», 29 de enero de 2017, disponible en bit.ly/30SZLGK.

14. Julio Nahuelhual, «Andrés Concha: «Hay que buscar fórmulas para que Enap actúe como empresa independiente del gobierno"», La Tercera, 23 de enero de 2011, disponible en bit.ly/3nksbt1. 


\section{Instrumentos económicos: impuesto verde}

Además de los incentivos directos y de las normas comando y control en detrimento de las energías tradicionales, también se ha buscado promover las energías renovables por la vía de un impuesto pigouviano a las fuentes contaminantes. En definitiva, ya sea con fines de recaudación tributaria, pero también de dar señales correctas, se implementó el llamado impuesto verde. Así es como, con motivo de la Reforma Tributaria de 2014, mediante la Ley $20.780^{15}$ se procedió a gravar las emisiones de contaminantes como el óxido de nitrógeno (NOx) y el dióxido de carbono $\left(\mathrm{CO}_{2}\right)$. Tratándose de este último, se definió una tasa de US $\$ 5$ por tonelada emitida por fuentes fijas, cuando se trata de calderas o turbinas que, individualmente o en su conjunto, sumen una potencia térmica de $50 \mathrm{MWt}$.

Pese a que se fue incorporado en la Reforma Tributaria de 2014, su implementación comenzó desde el año 2017. Su aprobación fue acompañada de bastante retórica ambiental, sin embargo, el impuesto verde no ha cumplido del todo su finalidad ambiental y ha sido efectivo solo desde la perspectiva recaudatoria. ${ }^{16}$ Esto se debe a que la norma aprobada (inciso final del artículo 8 de la Ley 20.780) señaló que este impuesto «no deberá ser considerado en la determinación del costo marginal instantáneo de energía, cuando este afecte a la unidad de generación marginal del sistema».

Vale decir, el impuesto no se considera como costo marginal para determinar el orden de mérito en el despacho y, por lo tanto, no se considera para determinar el orden en que las distintas centrales son llamadas a generar para proveer de suministro eléctrico al sistema eléctrico nacional. Esto hace que funcione, en la práctica, como un impuesto con fines recaudatorios, pero no como un impuesto pigouviano que inhiba la generación termoeléctrica o que incentiva a las energías renovables.

\section{Tratados internacionales}

También se debe considerar el derecho internacional, pues Chile ha firmado tratados que han promovido el desarrollo de las energías renovables. Así se observan dos tratados en especial: el Protocolo de Kioto y el Acuerdo de París.

15. Ley 20.780, reforma tributaria que modifica el Sistema de Tributación de la Renta e introduce diversos ajustes en el sistema tributario, de 29 de septiembre de 2014. Disponible en bit.ly/2IOqcy2.

16. «La recaudación fiscal correspondiente a emisiones fijas aportó al fisco un total de US\$191,3 millones, pagados por las empresas afectadas por este «impuesto verde», a lo que se añade lo recaudado por fuentes móviles (automóviles y camiones), equivalente a US\$ 107 millones». García Bernal, Nicolás. (2018) Implementación del Impuesto Verde en Chile. Disponible en bit.ly/3merekA. 


\section{Protocolo de Kioto}

El Protocolo de Kioto adoptado en diciembre de 1997 en la Tercera Conferencia de las Partes de la Convención Marco de las Naciones Unidas sobre el Cambio Climático, introdujo ciertos instrumentos denominados «mecanismos de flexibilidad» $\mathrm{O}$ «mecanismos de Kioto»; el mecanismo de desarrollo limpio es el aplicable a Chile. Mediante este instrumento, los países desarrollados pueden financiar proyectos de captura $o$ abatimiento de gases de efecto invernadero en otras naciones - principalmente en vías de desarrollo-, acreditando tales disminuciones como si hubiesen sido realizadas en territorio propio. Esto abarata significativamente los costos de cumplimiento.

En concreto, el Protocolo de Kioto permite que una empresa chilena que disminuye sus emisiones de $\mathrm{CO}_{2}$ pueda vender esta reducción a empresas de países desarrollados que estén obligadas a reducir sus emisiones. Para diversos proyectos de energías renovables, el Protocolo de Kioto ha constituido una fuente de ingresos adicionales a sus ventas de energía y potencia, por lo cual se transforma en un incentivo directo, que emana de un tratado internacional.

El mercado del Mecanismo de Desarrollo Limpio inició sus operaciones incluso antes de la entrada en vigencia del Protocolo de Kioto y, durante algunos años previos a la Convención de París, lo que fue muy dinámico. Actualmente, en el contexto de la Convención Marco de las Naciones Unidas para el Cambio Climático, se registran 7.807 proyectos de todo el mundo a través de este mecanismo. De acuerdo con el análisis de dicho registro, Chile cuenta con 78 proyectos de energías renovables registrados, aunque no todos ellos han sido ejecutados finalmente. ${ }^{17}$ Muchos se registraron, emitieron Certificados de Reducción de Emisiones (CER), pero solo algunos lograron obtener ingresos por la venta de ellos, mientras que muchos otros no llegaron a verificar sus emisiones, por lo cual nunca lograron monetizar estos bonos de carbono, debido a lo caro y engorroso de algunos procedimientos, que no se llegaron a pagar por la baja en los precios de dichos certificados. Cabe señalar, sin embargo, que en el último tiempo se ha reanudado la venta de Certificados de Reducción de Emisiones, premiando a las energías renovables que se registraron en su momento.

\section{Acuerdo de París}

El Acuerdo de París ${ }^{18}$ compromete a cada uno de los 196 países firmantes a preparar, comunicar y mantener Contribuciones Determinadas a Nivel Nacional, las que definen los esfuerzos de la acción climática de cada país, para reducir las emisiones y adaptarse al cambio climático. Las Contribuciones Determinadas a Nivel Nacional

17. Buscador del listado de proyectos que contempla el Clean Development Mechanism, uno de los mecanismos del Protocolo de Kyoto. Disponible en bit.ly/2WhiRtW.

18. Organización de las Naciones Unidas, Acuerdo de París (2005), disponible en bit.ly/30KtKAO. 
se presentan cada cinco años a la secretaría de la Convención Marco para el Cambio Climático y presentarán una progresión en comparación con la contribución anterior presentada por cada Estado.

La primera Contribución Determinada de Chile fue aprobada por el Consejo de Ministros para la Sustentabilidad en el $2015^{19}$ y contiene cinco componentes: mitigación de gases de efecto invernadero y contaminantes climáticos de vida corta; adaptación; construcción y fortalecimiento de capacidades; desarrollo y transferencia de tecnologías; y financiamiento climático.

Uno de los puntos discutidos en Madrid, en la COP 25 que debía realizarse en Santiago, fue la posible aplicación del artículo 6 de este Acuerdo que permite, precisamente, establecer mecanismos de compensación de emisiones entre los países signatarios, con miras a facilitar el cumplimiento de sus compromisos.

El Acuerdo de París es de vital importancia y puede ser la justificación última de todos los esfuerzos que se realicen para promover las energías renovables. Sin embargo, como tratado internacional en sí mismo, no contiene beneficios directos para la generación de estas energías, como sí las tenía el Protocolo de Kioto. La única posibilidad de que el Acuerdo de París también constituya un incentivo en sí mismo es que se incorporen mecanismos de cooperación o de compensación. Estos mecanismos de incentivo proporcionan «una señal de precio del carbono al sector privado, lo cual es clave para internalizar y enfrentar los riesgos del cambio climático de manera adecuada en el futuro» (Patrickson, 2019).

\section{Acuerdos voluntarios}

Las decisiones vinculantes adoptadas por órganos públicos no son los únicos instrumentos de protección ambiental disponibles. También existen aquellos actos voluntarios, adoptados en virtud de la responsabilidad social empresarial o motivados por la persuasión moral, para dar respuestas a una ciudadanía cada vez más consciente y preocupada por el cambio climático.

\section{Acuerdo Voluntario de Descarbonización}

Entre los diversos instrumentos de política ambiental presentes en esta materia se puede apreciar la presencia de un importante acuerdo voluntario: el acuerdo de descarbonización. Obedeciendo a una invitación del Gobierno de Chile, en enero de 2018, las empresas de generación termoeléctrica firmaron un compromiso de retiro y reconversión de unidades a carbón, compromiso que se materializó a través de la

19. Consejo de Ministros para la Sustentabilidad, Acta sesión Ordinaria $N^{\circ}$ 3/2015 de 14 de septiembre de 2015, disponible en bit.ly/2WgB3UD. 
denominada «Mesa de Descarbonización», ${ }^{20}$ que analizó los diversos aspectos involucrados, tales como impacto económico, medioambiental y social de este proceso.

El compromiso adquirido por las empresas consistió en, primero, no iniciar nuevos desarrollos de proyectos a carbón que no cuenten con sistemas de captura y almacenamiento de carbono. Segundo, un cronograma para el cese programado y gradual de operación de centrales a carbón y, por último, la participación en una mesa técnica convocada por el Ministerio de Energía para implementar estos ambiciosos compromisos.

La Mesa de Descarbonización concluyó en enero de 2019, tras meses de sesiones de trabajo, con una serie de compromisos, ${ }^{21}$ entre los cuales se encuentra que a 2024 concluirán sus operaciones las ocho termoeléctricas más antiguas del país, compromiso que ha sido ratificado e incluso ampliado, con el anuncio de cierre de Bocamina I y II, lo que no formaba parte del anuncio original.

En términos de contribución a la promoción de las energías renovables, esta medida voluntaria no puede sino ser catalogada como de alta efectividad.

\section{Clientes privilegian energía de fuentes renovables como parte de su responsabilidad social}

Últimamente, numerosas empresas han decidido comprar energía proveniente de fuentes renovables, como una forma de mostrar compromiso con el medio ambiente, como parte de lo que se denomina Responsabilidad Social Empresarial y también como instrumento de marketing, gracias a la creciente preocupación ciudadana por el cambio climático.

Estos esfuerzos voluntarios, basados en lo que se denomina «persuasión moral», también forma parte de los instrumentos de gestión ambiental de carácter voluntario. De hecho, para la recuperación de la capa de ozono es sabido que el compromiso voluntario de fabricantes de aerosoles y equipos que producían clorofluorocarbonos fue clave para la sustitución tecnológica de estos componentes.

Sin embargo, en el caso de la energía es complejo de certificar, dado que es imposible asegurar que Metro de Santiago, por nombrar alguna de las empresas que han asegurado que su suministro será totalmente proveniente de fuentes renovables, ha utilizado solo electrones efectivamente producidos por estas energías. La energía es fungible y toda la energía de un sistema eléctrico se transa de forma conjunta.

20. Ministerio de Energía, «Mesa de Trabajo de Descarbonización», disponible en bit.ly/2IQsQTX.

21. «Es un hito histórico, no hay ningún otro país en vías de desarrollo que ha firmado o ha logrado un acuerdo como este y además que tenga la participación que tiene el carbón en la matriz», señaló la ministra de Energía, Susana Jiménez. Francisca O’Ryan, «Mesa de descarbonización concluye con positivo balance de la industria», La Tercera, 4 de enero de 2019, disponible en bit.ly/2K6Rss7. 
Por ello, actualmente el Coordinador Eléctrico Nacional se encuentra implementando un programa llamado «Plataforma de trazabilidad de compromisos de contrato de energía renovable», que busca dar certeza de que las empresas interesadas en adquirir $-\mathrm{y}$ difundir que lo hacen - solo energías renovables, efectivamente lo estén haciendo, sin incurrir en declaraciones engañosas, ni doble conteo de la energía renovable utilizada. Para ello, busca crear un registro de Certificados de Origen Renovable (COR), a través de un sistema de blockchain, que permita dar trazabilidad, asegurando a los clientes que compren energía renovable, que realmente proviene de estas fuentes ${ }^{22}$. Este programa debiera estar operativo en el año 2021, según lo ha anunciado el coordinador.

\section{Evaluación de políticas públicas implementadas}

Las razones que justifican que haya incentivos a la introducción de energías renovables a la matriz energética son exclusivamente sus beneficios ambientales. Por ello, si existe una justificación por promover este tipo de generación eléctrica, es porque se está ante una política pública ambiental, aunque la mayoría de las medidas analizadas anteriormente sean normas propias de la industria eléctrica.

\section{Mezcla de paradigmas de políticas públicas}

Como se puede apreciar, el listado de medidas o instrumentos es largo. Algunos creados directamente para promover a las energías renovables, mientras que otros promueven las energías renovables sin habérselo planteado directamente, como es el caso de las normas de emisión para termoeléctricas o la propia judicialización de grandes proyectos de energía tradicional.

Dicho lo anterior, se puede observar que el enfoque de las políticas públicas es heterodoxo, porque combina políticas públicas tradicionales - normas de regulación directa o comando y control-, como es el caso de las normas de emisión para termoeléctricas o la evaluación de impacto ambiental y que ha resultado ser de difícil calificación favorable por parte de los proyectos de energía tradicional, con otras políticas públicas descentralizadas, del tipo acuerdos voluntarios o «persuasión moral» e incentivos, que actúan en forma de incentivos directos a las Energías Renovables No Convencionales o de incentivos indirectos, como es el caso de los impuestos verdes. Es decir, una primera observación es que estas políticas mezclan enfoques o paradigmas, tal como se observa en la figura 1.

22. Pilar Sánchez, «El Coordinador Eléctrico de Chile propone crear certificados de origen voluntarios», PV Magazine, 14 de enero de 2020, disponible en https://bit.ly/3qY8cTb. 


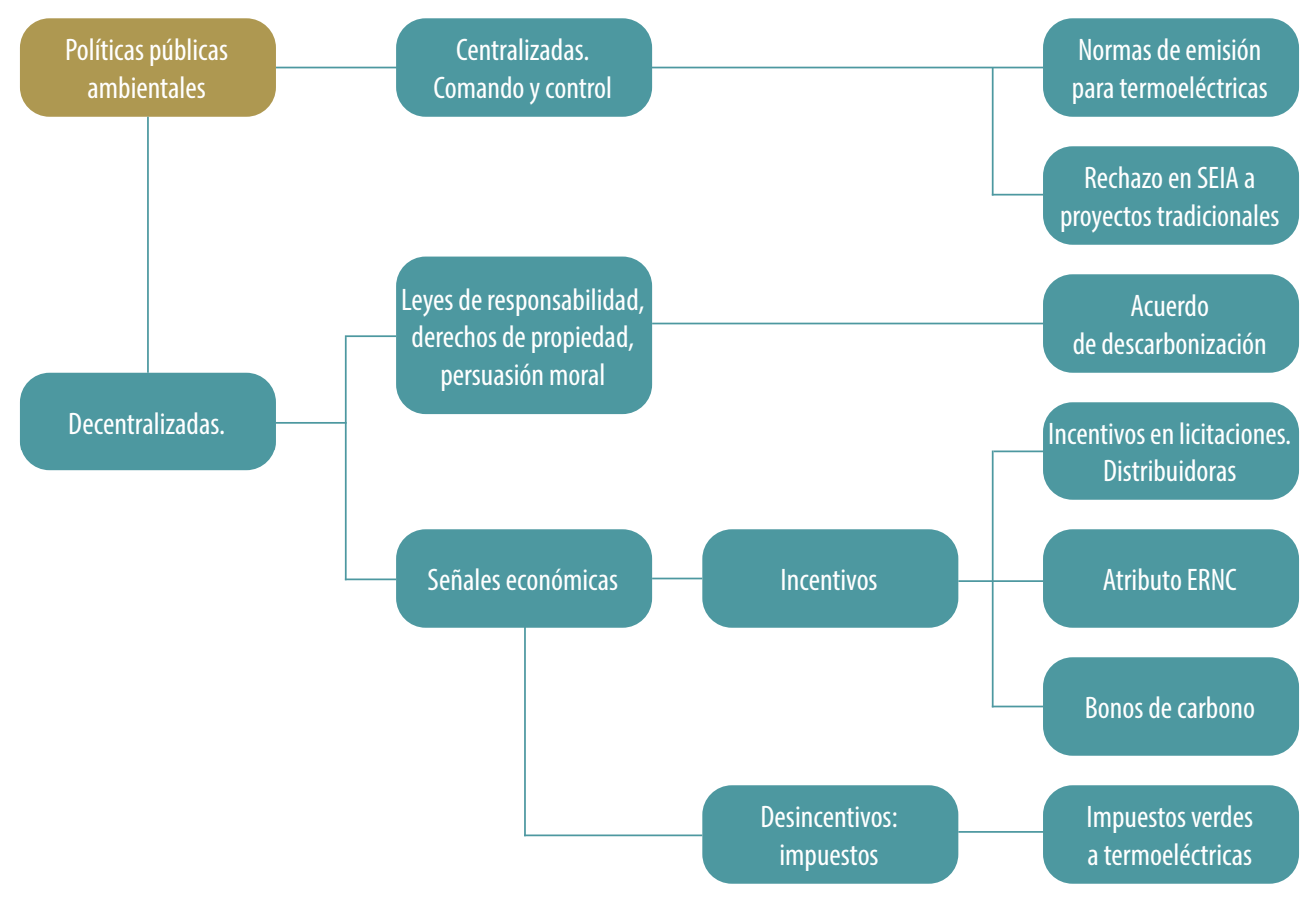

Figura 1. Enfoques o paradigmas de políticas públicas implementadas

El regulador ha buscado y utilizado prácticamente todos los modelos de instrumentos o políticas públicas disponibles para promover a las energías renovables, aunque en muchos casos con poca determinación o con insuficiente fuerza, como es el caso del atributo ERNC y del impuesto verde. Tal vez la razón es su intención de incentivar estas nuevas energías pero no de una manera tan determinante como para renunciar abiertamente al principio de neutralidad tecnológica.

Otro aspecto relevante es que en esto han actuado los tres poderes clásicos de la institucionalidad. La mayoría de las iniciativas han provenido del Ejecutivo, es cierto, pero el Congreso Nacional ha sido muy determinante y hasta los Tribunales de Justicia han jugado un rol, especialmente en dificultar la viabilidad de diversos proyectos de energía tradicional.

\section{Análisis de efectividad de cada una de las medidas propuestas}

Expuestas las políticas que expresa o involuntariamente han fomentado la incorporación de energías renovables, se tratará de dilucidar cuáles de ellas han tenido mayor y menor efectividad. Para tal efecto, se han catalogado las medidas en tres grupos: las de baja, alta y mediana efectividad, que sin ser determinantes han contribuido a generar un ambiente propicio para el desarrollo de las energías renovables. 


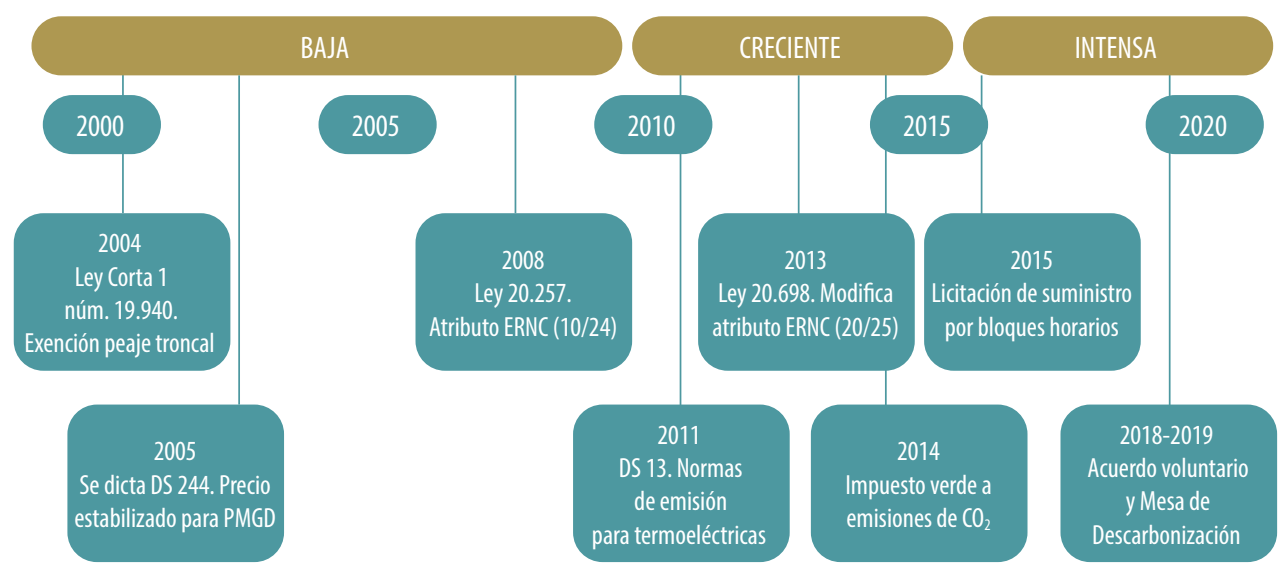

Figura 2. Línea temporal de los instrumentos implementados.

La clasificación que se ha hecho no está exenta de cierta discrecionalidad, pero se han utilizado algunos criterios. Uno de ellos es el análisis temporal: medidas que se implementaron antes del auge de las energías renovables y que no lograron producir el efecto deseado. Una línea temporal de los instrumentos implementados se muestra en la figura 2.

Tal como se puede observar en la figura 3, el impacto de las primeras medidas implementadas fue muy bajo y solo a partir del año 2014-2015 en adelante es que se empieza a apreciar un crecimiento significativo de la incorporación de las energías renovables en la matriz energética local, sin perjuicio de que las primeras medidas de todos modos hayan contribuido a crear un escenario favorable y una señal positiva para la incorporación de estas energías.

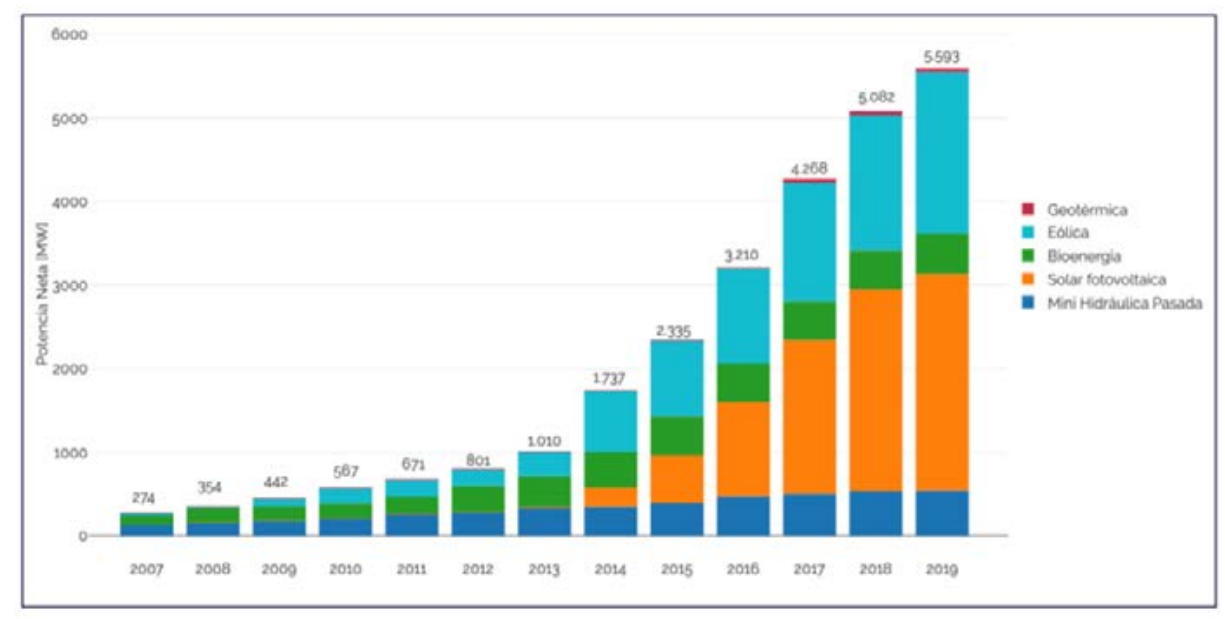

Figura 3. Impacto de la incorporación de las energías renovables en la matriz energética chilena 
Otro criterio que se ha utilizado es el análisis individual de cada medida y sus impactos en la industria. Es difícil aislar el efecto agregado de una medida sobre otra. Y también excede de este análisis la posibilidad de aislar otros efectos que también han contribuido al fomento de las energías renovables y que no obedecen a decisiones de Estado, en especial la determinante reducción de costos provocado por la innovación tecnológica, especialmente en materia de energía eólica y solar.

Con todo, se realiza la siguiente clasificación de medidas, de acuerdo con su efectividad.

\section{Medidas de baja efectividad}

En primer lugar, dado que son variados los mecanismos mencionados, se partirá por descartar algunos que han considerado como menos efectivos.

\section{Exención de peaje troncal}

Esta fue una de las primeras medidas implementadas, pero de muy bajo impacto. Tanto es así que fue derogada, como se señaló, cuando se modificó la Ley General de Servicios Eléctricos mediante la Ley de Transmisión, que no afectó en términos de pérdidas de beneficios a las energías renovables. No hubo mayores reclamos, por el contrario, es en los últimos años sin contar con este beneficio, que se ha producido el mayor crecimiento de nuevos proyectos y generación eléctrica en base a energías renovables.

\section{Atributo ERNC}

El incentivo cumplió un rol importante en cuanto a dar una señal de voluntad política, una especie de renuncia parcial al principio sacro santo de neutralidad tecnológica que inspira la legislación eléctrica y dispuso metas de penetración de las energías renovables en la matriz energética chilena. Generó debate político y visibilidad al tema. Todo eso es relevante, sin embargo, en cuanto a si logró motivar inversiones por parte de las empresas generadoras, es más discutible, dada la poca importancia de los potenciales ingresos que significa en la evaluación de proyectos. Esto fue agravado porque la inversión en energías renovables fue aumentando por sobre lo esperado, y eso hizo que los valores del atributo ERNC fuera disminuyendo como consecuencia de lo anterior. Se podría decir, por tanto, que el atributo ERNC fue víctima del éxito de las energías renovables en Chile, más que una causa de este. La figura 4 explica esta afirmación.

La generación de Energías Renovables No Convencionales superó ampliamente las metas definidas en la obligación legal. Mientras más amplia es esta superación, más se reduce el valor del atributo ERNC y, por tanto, menor es su aporte como política pública destinada a incentivas la incorporación de estas energías al país. 


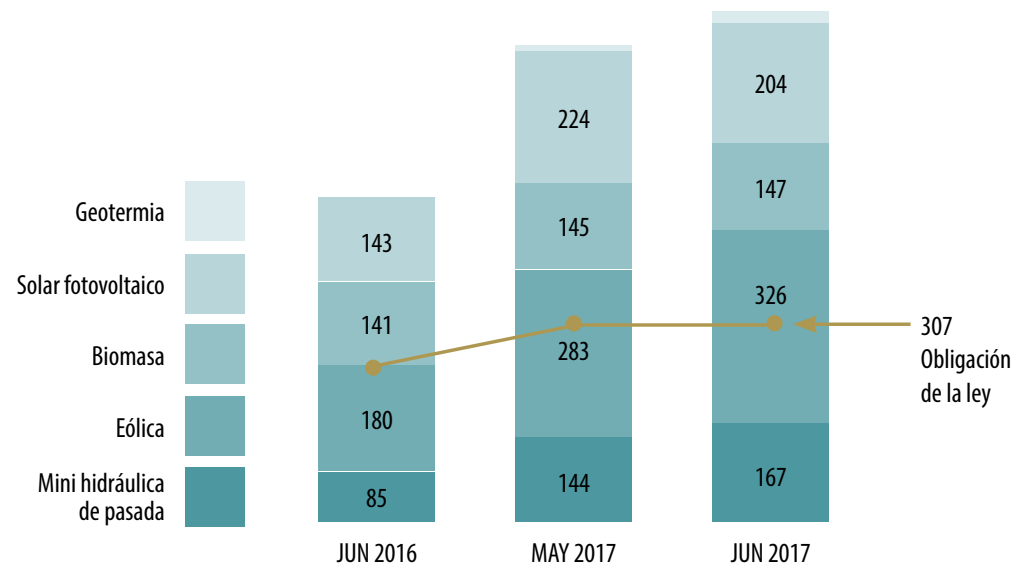

Figura 4. Cumplimiento de leyes ERNC por tecnología.

\section{Impuesto verde}

El impuesto verde también califica como de baja efectividad. La decisión de no incluir el impuesto en el costo marginal de las empresas generadoras a las que se les aplica tuvo por objeto evitar que el costo del impuesto fuese traspasado a precio al cliente final - tanto en el mercado spot, como luego en los propios contratos- y quedara radicado en los márgenes de los generadores.

Consecuentemente, se dispuso que aquellas unidades cuyo costo total unitario sea mayor o igual al costo marginal, deberán recibir una compensación -independiente de si son contaminantes. Esto provoca el contrasentido que empresas han terminado pagando también parte del impuesto, tal como lo explica García Bernal (2018: 1):

Según el balance del primer año de implementación del gravamen, se evidenció que más de 5 mil millones de pesos recaudados fueron pagados por centrales de energías renovables, lo que sería equivalente al 4,75\% del total de lo recaudado. Además, indica que la compensación para el ejercicio del año 2017 ascendió a \$16.306 millones de pesos (aproximadamente US $\$ 25$ millones), equivalente a un $14,9 \%$ del total de impuesto pagado por las empresas generadoras. ${ }^{23}$

Más allá de quién paga y cuánto, el problema es que no se está dando la señal económica que busca un impuesto verde. La Ley 20.780 de Modernización Tributaria, modificó el impuesto verde para establecimientos industriales, mejorando el sistema

23. Destaca, por ejemplo, que ENGIE - la principal empresa con propiedad de termoeléctricas en Chile- fue compensada en un 54,41\% de lo tributado, pagando menos de la mitad de lo que le correspondería. Así también, a Enel Generaciones Chile, AES Gener y Colbún se les compensó el 10,4\%, 6\% y $1,56 \%$, respectivamente. 
actual, pero dejando pasar una oportunidad tremenda (Pérez, 2020), pues no solo dejó la tasa al mismo valor - lo que habría sido bueno en términos ambientales-, sino que además mantuvo la norma de que no se considera el costo del impuesto para determinar el costo marginal del sistema, lo que era imprescindible.

Por ello, siendo el impuesto verde un mecanismo de extraordinaria efectividad en la literatura, en el caso de Chile se concluye que esta es una medida que ha sido de baja efectividad en materia de promoción de las energías renovables y que si se quiere aprovechar bien - que por ahora solo opera bien desde la óptica recaudatoria-, se debiera incorporar este impuesto en el costo marginal y por ende en el cálculo del orden de mérito para el despacho de las centrales de generación.

\section{Medidas de alta efectividad}

Entre las medidas de mayor efectividad se han seleccionado las siguientes:

- Cambios en mecanismos de licitación de suministro de las empresas de distribución, como licitación por bloques horarios y otros.

- El Precio Estabilizado para Pequeños Medios de Generación Distribuida (PMGDs), que han probado ser muy relevantes a la hora de promover el crecimiento de las energías renovables.

- El Acuerdo Voluntario de Descarbonización, que en caso de que se cumpla lo comprometido, será una reducción muy significativa de gases de efecto invernadero.

Curiosamente, las dos primeras medidas fueron implementadas sin el debate público del atributo ERNC, ni la discusión mediática del impuesto verde. Por el contrario, estos mecanismos fueron implementados principalmente por la vía administrativa, aun cuando en ambos casos hay disposiciones legales que los amparan. Estos han sido decisivos en la incorporación de las energías renovables en la matriz energética chilena.

Como se vio anteriormente, la licitación de suministro por bloques horarios, y otros incentivos para los desarrolladores, fueron de un enorme éxito. Estas licitaciones les dieron a las empresas lo que por mucho tiempo andaban buscando y no podían conseguir: contratos de suministro de energía. Con ellos, los bancos comenzaron a proveer los créditos necesarios para financiar la ejecución de los proyectos de energías renovables. Se llevaba años en que los proyectos se diseñaban, se aprobaban ambientalmente, se obtenían los permisos, pero no se podían ejecutar por falta de financiamiento, con excepción de algunos proyectos de carácter más bien demostrativo. Las nuevas subastas significaron el esperado despegue de estas tecnologías de generación. Tanto es así, que se dejó de hablar de «energías alternativas». Las energías renovables pasaban a ser la regla dominante en la planificación de nuevos proyectos de generación. 
Las facilidades en las licitaciones de suministro le dieron a la industria lo que esta andaba buscando: contratos que permitieran acceder al financiamiento bancario. No se requería subsidios porque los precios eran altos. No se requería cuotas, porque estas no lograban hacer la diferencia. Lo que se requería era un contrato para poder acceder al financiamiento bancario.

Respecto de las licitaciones, a una conclusión similar llega Sebastián Leyton:

El sistema de licitaciones creado con la modificación de la Ley General de Servicios Eléctricos con la Ley 20.698, mediante la incorporación del artículo 150 ter, vino a establecer otra alternativa para la comercialización de proyectos de generación en base a energías renovables no convencionales. Lo anterior es altamente valorable, puesto que evita que los proyectos ERNC se vean limitados a comercializar su generación en el mercado de contratos de suministro (el cual se encontraba en parte limitado por factores propios de las características de generación de dichos proyectos en relación a las necesidades de los clientes) y del mercado spot (con el riesgo de mercado asociado y menor predictibilidad en término de ingresos) (Leyton, 2014: 16).

También es posible afirmar que ha sido exitoso el caso del precio estabilizado, al que pueden acceder los Pequeños Medios de Generación y de Generación Distribuida. La base de su éxito es que esta figura constituye un equivalente a un contrato, que permite a los desarrolladores de proyectos acceder a financiamiento bancario.

Últimamente se ha iniciado un proceso de revisión de la normativa que regula este tipo de proyectos, debido a que en ciertas barras se producen distorsiones en el precio, vale decir, el costo marginal difiere mucho del precio estabilizado. La diferencia de precios que se produce cuando el costo marginal es inferior al precio estabilizado que se paga a los proyectos que se acogen a ese régimen debiendo ser asumida por todos los actores del mercado eléctrico que retiran energía, con lo cual se produce una transferencia económica desde otros generadores a esos Pequeños Medios de Generación y de Generación Distribuida, dada la distorsión descrita. Lo anterior suele deberse a que el precio estabilizado es un valor que no varía durante el día, mientras que la curva de Costos Marginales sí, debido a que a ciertas horas se genera una inyección de energía solar de bajo costo marginal. Por esa razón, la forma en que se calcula el precio estabilizado se encuentra sujeto a revisión por parte de la autoridad.

La generación de estos pequeños medios ha crecido de manera relevante en los últimos años, aun cuando sigue siendo un porcentaje bajo en comparación con proyectos de mayor escala. De todos modos, un estudio de la Universidad de Chile cuantifica en un $8,7 \%$ la reducción de generación eléctrica en base a carbón gracias a ellos, y considera que las pérdidas del sistema de transmisión se han reducido en $43 \mathrm{GWh}$, lo cual constituye otro beneficio de estas pequeñas centrales (Matus y otros, 2019). En efecto, los Pequeños Medios de Generación Distribuida al conectarse directamente 
al sistema de distribución, cerca de los polos de consumo, la energía inyectada viaja menor distancia y se utiliza menos el sistema de transmisión eléctrico, lo que hace que haya menos pérdidas de energía, las que se generan mientras más distancia recorre la energía inyectada.

Sin desconocer obviamente la relevancia del valor final al que se defina este precio estabilizado, lo que se concluye es que precisamente lo importante es que haya un monto estable asegurado, pues eso es lo que permite a los Pequeños Medios de Generación y de Generación Distribuida acceder al financiamiento bancario, cuya carencia en el pasado es lo que les había impedido desarrollar sus proyectos.

Una tercera medida de alta efectividad es el Acuerdo Voluntario por la Descarbonización, que luego se materializó en un compromiso mediante la denominada «Mesa de Descarbonización» en un plan con el mismo nombre. Este plan considera el retiro de ocho centrales a carbón en cinco años, lo que permitirá eliminar 1.047 MW. Luego, en una etapa de mediano plazo, contempla establecer cronogramas específicos de retiro, hasta llegar a la paralización del parque total de centrales a carbón antes de 2040.

Lo que más llama la atención de este importante acuerdo es que constituye un acuerdo voluntario. Paradojalmente, este acuerdo se logró al margen del Comité de Producción Limpia, instancia gubernamental que lleva años promoviendo este tipo de acuerdos. La crítica a este tipo de instrumentos es que, obviamente, carecen de «dientes» o mecanismos para instar en su obligatoriedad. Sin embargo, en este caso, el acuerdo voluntario se ha transformado en uno de los principales instrumentos de promoción de las energías renovables y de reducción del uso de combustibles fósiles para la generación eléctrica. En efecto, todo hace pensar que las energías renovables son las llamadas a reemplazar esos MW térmicos que se dejarán de producir con motivo del plan.

\section{Medidas de efectividad indeterminada}

Las medidas de baja y alta efectividad parecen más simples de juzgar, e incluso puede ser estimada su capacidad de reducción de la carbonización medida a medida. Sin embargo, hay también un conjunto de medidas o instrumentos que pueden haber jugado un rol fundamental, pero que es más difícil de calcular o evaluar.

Tal es el caso de normas que crearon un escenario favorable para la irrupción de las energías renovables, en particular se hace referencia a la paralización y la judicialización de proyectos de energías tradicionales a través del Sistema de Evaluación de Impactos Ambientales y de los Tribunales de Justicia. Sin entrar al mérito de cada una de esas decisiones, el hecho de que proyectos tan relevantes como HidroAysén, Energía Austral Río Cuervo, Castilla, Barrancones, solo por nombrar algunos, no se hayan materializado, es que se produjo un espacio muy relevante para las energías renovables. 


\section{Conclusiones}

Hoy se está viviendo una profunda transformación debido a la incorporación masiva de energías renovables y a futuros cambios como la electromovilidad, almacenamiento de energía y autoconsumo. El Estado ha permanecido como regulador, bastante activo por lo visto, permitiendo que sea el mercado y el sector privado el que lidere esta profunda transformación.

No se puede desconocer la importancia de los cambios realizados. Solo hace 7 años la prensa relataba la crisis del sector energético titulando: Tormenta perfecta: sin ministro, sin agua, sin proyectos y con riesgo de apagones en $2014 .{ }^{24}$ Hoy la situación es radicalmente distinta. Se ha invertido en energía más que en minería y que en infraestructura en los últimos años. Esto ha permitido reducir los precios de más de $200 \mathrm{U} \$ / \mathrm{MWh}$ a valores cercanos a la cuarta parte y con una matriz mucho más renovable. Así, Chile se ha convertido en uno de los 10 países del mundo que más invierte en energía renovable y en paralelo las empresas de generación tradicional han iniciado la descarbonización de la industria y comprometido que no se construirán nuevas centrales a carbón.

\section{Análisis de instrumentos utilizados para la descarbonización} de la matriz energética

Es importante ser generosos al reconocer los méritos de las buenas políticas, especialmente cuando ellas son ingeniosas y en vez de proponer más Estado para resolver problemas del mercado, lo que hacen es diseñar estímulos, para que este funcione mejor. Esta es la tesis del Premio Nobel de Economía Richard Thaler: la teoría nudge o del pequeño empujón. Los mercados muchas veces requieren que haya incentivos en la señal correcta para operar mejor. Tal es el caso de haber promovido licitaciones más flexibles, bloques horarios diseñados para aprovechar las horas de viento y radiación solar, cambios normativos para dar seguridad a los inversionistas, metas de generación renovable, entre otras iniciativas.

Factores externos también ayudaron, es cierto. Pero lo más importante es haber implementado políticas públicas modernas, diseñadas con amplio consenso político y por coaliciones gobernantes de distinto color político, que en vez de pelear por la paternidad de tal o cual idea, de tal o cual reforma, han intentado construir en forma colaborativa.

Como se puede observar, los instrumentos que se han utilizado en Chile para promover la integración de las energías renovables y la descarbonización de la matriz han sido diversos. Y más interesante aún, es que no se ha renunciado a los principios

24. Fundación Terram, «Tormenta perfecta: sin ministro, sin agua, sin proyectos y con riesgo de apagones en 2014", 2 de abril de 2012, disponible en bit.ly/34eMbWB. 
rectores del derecho eléctrico chileno de neutralidad tecnológica, operación a mínimo costo y sin subsidios.

Distinto a lo que se esperaba, no ha sido el atributo ERNC ni el impuesto verde, los instrumentos más efectivos. Ellos han acaparado mucho la atención pública, han tenido amplia discusión legislativa y gozan de enorme visibilidad. Sin embargo, por las razones que se han señalado, sus resultados han sido de baja efectividad. El atributo ERNC no apuntaba a lo que los desarrolladores de energías renovables necesitaban. Los precios eran altos, no se necesitaba un pequeño delta adicional. Lo que los desarrolladores realmente necesitaban era tener contratos de suministro - que los obtuvieron en las licitaciones de las empresas de distribución- o a través de su sucedáneo, el autodespacho y el precio estabilizado que se les ofreció a los Pequeños Medios de Generación y de Generación Distribuida.

El impuesto verde, por su parte, al no afectar el costo marginal ni la orden de mérito con que se ordena el despacho del suministro eléctrico, tampoco logra actuar como una señal de precio en el sistema eléctrico.

Las medidas que sí han sido efectivas, en cambio, son aquellas de las que tal vez menos se esperaba: los incentivos en las licitaciones de suministro para las empresas de distribución, el precio estabilizado y el autodespacho para los Pequeños Medios de Generación Distribuida y el Acuerdo Voluntario para la Descarbonización.

\section{Los efectivos nudges que motivaron el auge de las energías renovables}

Este conjunto de instrumentos exitosos son incentivos sutiles, pero bien diseñados, gozaban de un buen diagnóstico y han apuntado bien al fin perseguido. Son lo que el Premio Nobel de Economía Richard Thaler llamaría un nudge, un pequeño empujón. El mérito es que estos incentivos, a veces sutiles, han sido capaces de afectar la arquitectura de las decisiones (Sunstein y Thaler, 2017).

En efecto, los instrumentos que se han catalogado como los más efectivos distan mucho de ser los incentivos fuertes, como los esquemas de feeding tariffs que se han utilizado en otros países que, por ser tan amplios y cuantiosos, terminaron siendo insostenibles en el tiempo. Los gobiernos de Europa han tenido que desmantelarlos, incluso con efecto retroactivo, lo que fue desastroso hace una década para la naciente industria de energías renovables europea.

Tal vez en algunos casos no se trate de empujones puros, como ocurre con la simple entrega de información a las personas. ${ }^{25}$ Solo la eventual implementación de una

25. Un claro ejemplo de nudge puro, o de información, en el sistema eléctrico, es el de la iniciativa cuentas claras, simples y transparente», que se implementó el año 2014, que tenía por objeto «conocer la percepción de la ciudadanía acerca del contenido de las boletas de consumo de gas y electricidad» (Ponce de León Solís, 2019; 350). 
plataforma de registro de Certificados de Origen Renovable podría calificar en esta categoría. Algunas de las medidas que se califican como empujones también incorporan transferencias en el riesgo - los cambios en las subastas reducen la prima por riesgo de las generadoras, lo que mejoró la competitividad de las energías renovables - o incluso mayores beneficios - el precio estabilizado de los Pequeños Medios de Generación Distribuida no es solo un precio garantizado, sino que también en algunas horas del día un precio mejor, más alto. Pero en general se está hablando de cambios sutiles, destinados a proporcionar mayor estabilidad y mejor información.

La mejor prueba de lo anterior es que las medidas señaladas como más efectivas — cambios en las subastas, precio estabilizado y acuerdo voluntario- no reciben subsidios públicos, ni cuestionan significativamente el principio de neutralidad tecnológica. No se sabe, por ejemplo, de acciones judiciales o administrativas realizadas por los demás actores del sector eléctrico en contra de estas medidas y sus posibles beneficiados.

El salto efectivo de las energías renovables se produce cuando se identifica realmente el problema que les impedía su incorporación al sistema eléctrico y se les apoya en superar este obstáculo. El problema, como se ha dicho, no era económico: los precios de la energía ya estaban lo suficientemente altos y los costos de generación bajaban día a día. El problema era el acceso al financiamiento de sus proyectos. Las energías renovables requerían estabilidad, certeza y contratos. Acceder a un Power Purchase Agreement era el sueño, el anhelo, el deseo que les permitiría hacer realidad sus promesas. Por ello, los cambios al sistema de subastas, que les permitieron acceder a estos contratos, como también la normativa de los Pequeños Medios de Generación Distribuida, que hace las veces de contrato de suministro porque da certeza a los bancos, fueron las claves de la transformación energética chilena.

Las energías renovables hoy proporcionan precios más bajos y una industria de generación más competitiva. Pero la principal motivación de su promoción es por razones ambientales y su capacidad para sustituir la emisión de gases de efecto invernadero. Se está hablando, por tanto, que la promoción de las energías renovables es una política netamente ambiental. En este sentido, la combinación de instrumentos que se ha descrito ha sido efectiva porque ha permitido que el mercado funcione mejor. Al decir de los propios autores de la teoría de los nudges:

La mayoría de los especialistas piensa que los sistemas como este, basados en los incentivos, deberían desplazar la regulación de mando y control. Nosotros estamos de acuerdo. Los enfoques basados en los incentivos son más eficientes y eficaces, y también aumentan la libertad de elección (Sunstein y Thaler, 2017: 215).

Afirman además que «casi siempre el mejor enfoque a los problemas de contaminación es gravar el comportamiento perjudicial y dejar que las fuerzas del mercado determinen la respuesta del costo incrementado» (Sunstein y Thaler, 2017: 214). 


\section{Nuevas políticas o instrumentos a implementar}

Aun así, todavía se tiene una alta proporción de la matriz sobre base carbón y gas natural. Es necesario revisar los instrumentos para que, siguiendo con los principios señalados, se pueda dar un empujón más grande a las energías renovables.

Una corrección del impuesto verde aparece como una medida muy recomendable, dado que el actual no ha cumplido con el propósito ambiental, por un error de diseño ya explicado: el que no afecta el orden de despacho de las centrales con que se construye la curva de oferta de suministro eléctrico.

Otro elemento para considerar es el necesario reemplazo de las centrales retiradas a carbón por energías renovables de base, como la geotermia, la concentración solar de potencia, de pumped storage y de almacenamiento. Este último será clave para poder aprovechar la enorme capacidad instalada de energías renovables que se está invirtiendo en estos años.

\section{Electrificación del transporte y de otras industrias}

Una matriz energética más verde y renovable permite pensar en la electricidad no como un problema, sino como una solución. El transporte es el segundo principal responsable en emisión de gases de efecto invernadero. Avanzar hacia un transporte eléctrico, especialmente el transporte público, constituye un real avance hacia un país carbono neutral. Pero solo en la medida que se cumpla el primer requisito, que la generación eléctrica sea predominantemente renovable.

\section{Metas versus instrumentos}

El debate permanente en el derecho ambiental sobre metas versus instrumentos lleva a poner énfasis, en materia de cambio climático, sobre los Planes Sectoriales de Mitigación y los de Adaptación al Cambio Climático. Tal como los anteriores debates sobre si privilegiar la aprobación de normas de calidad ambiental o priorizar los esfuerzos en las normas de emisión y en los otros instrumentos que son necesarios para lograr un mejor ambiente, se prevee que la discusión del Proyecto de Ley de Cambio Climático va a girar en torno a la meta, corriendo el riesgo de reducir el debate a los instrumentos que son los que en definitiva permiten alcanzar dicha meta. Desde los primeros Planes de Descontaminación de Santiago, la discusión era si bastaba ponerle a un sector industrial un objetivo o si era necesario regularlo en detalle. Lo mismo puede ocurrir en materia de cambio climático. El Ministerio de Minería no es capaz de comprometer reducciones de las empresas mineras, ni el de Agricultura las emisiones del sector agroindustrial. No tienen los instrumentos, ni las facultades. 
El cambio climático necesita instrumentos bien definidos, que apunten a la estructura de decisiones de los diversos actores. No bastan las declaraciones grandilocuentes, aunque tengan rango de ley.

Ciertamente, las metas ayudan a establecer instrumentos, les dan justificación y propósito. Pero eso no es automático. No porque la Ley de Cambio Climático diga que Chile será carbono-neutral al año 2050 o antes, se logrará serlo. Eso depende, fundamentalmente, de los Planes Sectoriales de Mitigación y los de Adaptación al Cambio Climático que se implementen. ${ }^{26}$

\section{Lecciones para la futura Ley de Cambio Climático}

Descarbonizar el planeta no es tarea fácil. El año 2020, la International Energy Agency (IEA) espera una reducción de un $8 \%$ en las emisiones de gases de efecto invernadero en comparación al año anterior, como una de las pocas cosas positivas que ha traído la pandemia del covid-19:

Esta caída muestra una verdad crucial para la crisis climática. Es una crisis muy grande como para ser resuelta mediante el abandono de aviones, trenes y autos. Incluso si las personas soportan grandes cambios en la forma en que llevan sus vidas, como este triste experimento ha demostrado, al mundo todavía le quedaría más del 90\% de la descarbonización necesaria para lograr el objetivo más ambicioso del acuerdo de París, que es que el clima sea solo un 1,5\% más cálido que antes de la revolución industrial (The Economist, 2020). ${ }^{27}$

En Chile, para descarbonizar la matriz de generación eléctrica se han utilizado los más diversos instrumentos, de los más diversos paradigmas normativos. Ha habido un esfuerzo inédito de todos los poderes del Estado. Aun así, las Energías Renovables No Convencionales representan solo un $20 \%$ de la generación. Esto va creciendo y si se agrega la generación hidroeléctrica de embalse se alcanzan niveles superiores al $50 \%$ de la matriz. Pero esto mismo demuestra lo difícil que es avanzar en reducir las emisiones de gases de efecto invernadero.

La Ley de Cambio Climático va a necesitar muchos recursos e instrumentos muy fuertes. La industria de generación eléctrica ha tardado años en cambiar su cultura. Las grandes empresas de generación, que no vieron venir estos nuevos tiempos, han

26. Si bien el debate público tiende a centrarse en la meta para alcanzar carbono neutralidad, principalmente, hay un interesante listado de medidas e instrumentos identificados en el Informe Final del Center for Climate and Resilience Research. (2020). Identificación de reformas legales para alcanzar la meta de carbono neutralidad en Chile al 2050. Santiago: Universidad de Chile. Disponible en bit. ly/3nkXfst.

27. The Economist, «Countries should seize the moment to flatten the climate curve», 23 de mayo de 2020, disponible en econ.st/2IOWjov. 
reaccionado tarde y han perdido importantes cuotas de mercado en el intertanto. La presión de los propios consumidores está jugando un rol cada vez más decisivo.

Es de esperar que se recoja esta experiencia en el diseño e implementación de los Planes Sectoriales de Mitigación y los de Adaptación al Cambio Climático de las demás industrias: el transporte, la ganadería, la minería, solo por nombrar algunas muy relevantes. Lograr reducciones significativas de gases de efecto invernadero es un esfuerzo titánico, un trabajo conjunto de los diversos poderes públicos, del sector privado y de los propios consumidores. No se debe subestimar la magnitud de este esfuerzo, pensando que bastará con que la Ley de Cambio Climático establezca metas y que la administración diseñe los planes sectoriales. La tarea es mucho más exigente que ese mero esfuerzo normativo.

\section{Referencias}

Bernstein, Sebastián, Gabriel Bitrán, Alejandro Jadresic y Marcelo Tokman (2013). Agenda para impulsar la generación eléctrica de base en el SIC. Informe para la Confederación de la Producción y el Comercio (CPC). Disponible en bit.ly/3gNfVyP.

Comisión Nacional de Energía (2017). Nueva Ley de licitaciones de suministro eléctrico para clientes regulados: un caso de éxito. Disponible en bit.ly/37jOHwp.

FABRA, Natalia, Juan Pablo Montero y Mar Raguant (2014). La competencia en el mercado eléctrico mayorista en Chile. Estudio requerido por la Fiscalía Nacional Económica. Disponible en bit.ly/3ny9wd6.

Galetovic, Alexander y Cristián Muñoz (2008). Energías Renovables No Convencionales: ¿Cuánto nos van a costar? Disponible en bit.ly/2WeOULd.

GARCÍA Bernal, Nicolás (2018). Implementación del Impuesto Verde en Chile. Disponible en bit.ly/34eZqqh.

Jiménez, Susana (2011). Energía Renovable No Convencional en Chile: Políticas de promoción en Chile y el Mundo. Disponible en bit.ly/2LFwvFh.

LeYTON, Sebastián (2014). «Licitaciones ERNC bajo la Ley 20.698. Lecciones del Renewable Auction Mechanism de California». Actas de Derecho de Energía. Disponible en bit.ly/3nQAGfD.

Libertad y Desarrollo, Temas Públicos. $\mathrm{N}^{\circ}$ 1.002, 28 de enero de 2011. Normas de Emisión para Termoeléctricas y Norma PM 2,5: un paso importante. Disponible en bit.ly/2Kws2nB.

Mardones, Marcelo (2019). «Los pequeños medios de generación distribuida ante el derecho de la energía. Régimen vigente, interpretaciones y prospectiva». Revista de Derecho Administrativo Económico, 29: 53-83. Disponible en bit.ly/2L4m51r.

Matus, Marcelo, Carlos Benavides, Rodrigo Sepúlveda, Erick Sierra, Juan Pablo San Martín y Sebastián Gwinner (2019). Análisis Costo/Beneficio de los Pequeños Medios de Generación Distribuida. Disponible en bit.ly/znzrkoB. 
Ministerio del Medio Ambiente (2018). Informe del Inventario Nacional de Gases de Efecto Invernadero de Chile, serie 1990-2016. Disponible en bit.ly/2IV9kpw.

Patrickson, Christian (2019). Artículo 6 del Acuerdo de París, Mecanismos de mercado y Ley de cambio Climático. Disponible en bit.ly/3nleOsE.

PÉrez, Clemente (2020). Impuestos verdes: una oportunidad perdida. Disponible en bit.ly/2KpzDVh.

Ponce De León Solís, Viviana (2019). «El nudge, su aplicación en el derecho chileno y sus potenciales problemas de constitucionalidad». Revista Chilena de Derecho 46 (2): 345-371. DOI: 10.4067/So718-34372019000200345.

RUDNICK, Hugh y Andrés Romero (2018). «Hacia un modelo en competencia: licitaciones de suministro eléctrico». En Máximo Pacheco (editor), Revolución Energética en Chile, 413-444. Santiago: Ediciones Universidad Diego Portales.

Sunstein, Cass y Richard Thaler (2017). Un pequeño empujón (Nudge). Madrid: Taurus.

\section{Sobre el autor}

Clemente Pérez Errázuriz es abogado de la Pontificia Universidad Católica de Chile, master en Políticas Públicas en Georgetown University (Estados Unidos), master en Administración de Empresas (MBA) de la Pontificia Universidad Católica de Chile. Además, es socio del Estudio Jurídico Guerrero Olivos y Director de ACERA (Asociación de Energías Renovables y Almacenamiento). (D) https://orcid. org/0000-0002-3480-7174. 
La Revista de Derecho Ambiental, del Centro de Derecho Ambiental de la Facultad de Derecho de la Universidad de Chile, es un espacio de exposición y análisis en el plano académico del derecho ambiental. Su contenido se presenta a través de doctrina, jurisprudencia y recensiones, y aborda diversas materias relacionadas con la gestión, institucionalidad y herramientas de protección ambiental y desarrollo sustentable. Se presentan artículos de diferentes autores y autoras en los que se analizan y abordan casos y temas jurídico-ambientales de creciente interés y actualidad.

\author{
DIRECTORA \\ Valentina Durán Medina \\ EDITORES \\ Jorge Ossandón Rosales \\ y Antonio Pulgar Martínez \\ SITIO WEB \\ revistaderechoambiental.uchile.cl \\ CORREO ELECTRÓNICO \\ revistada@derecho.uchile.cl \\ LICENCIA DE ESTE ARTÍ́CULO \\ Creative Commons Atribución Compartir Igual 4.o Internacional
}

La edición de textos, el diseño editorial

y la conversión a formatos electrónicos de este artículo

estuvieron a cargo de Tipográfica

(www.tipografica.io) 